\title{
PACMHCI V4 CSCW2 Oct 2020 Editorial
}

\author{
JUHO KIM, KAIST, South Korea \\ SIÂN LINDLEY, Microsoft Research, UK \\ SARITA SCHOENEBECK, University of Michigan, USA
}

CCS Concepts: • Human-centered computing $\rightarrow$ Collaborative and social computing; $\bullet$ Information systems $\rightarrow$ Collaborative and social computing systems and tools.

ACM Reference Format:

Juho Kim, Siân Lindley, and Sarita Schoenebeck. 2020. PACMHCI V4 CSCW2 Oct 2020 Editorial. Proc. ACM Hum.-Comput. Interact. 4, 2, Article 162 (October 2020), 1 page. https://doi.org/10.1145/3415161

We are delighted to welcome you to this issue of the Proceedings of the ACM on Human-Computer Interaction, which contains scholarship from the Computer-Supported Cooperative Work and Social Computing (CSCW) community. This is the second issue that represents the new quarterly submission model. This issue has 91 papers accepted from the January 2020 round (16 previously accepted papers from the January 2020 round were published in a prior issue and another 19 accepted this round will be published in a later issue). This indicates an overall $40.1 \%$ acceptance rate from the 310 submissions in January 2020. This issue represents the contributions of external reviewers, Associate Chairs, and the dedicated Editors, who were essential to carrying through the review process, especially during a global pandemic. As Papers Chairs, we are delighted to continue shaping and disseminating CSCW's tradition of high-quality scholarship.

Authors' addresses: Juho Kim, juhokim@kaist.ac.kr, KAIST, South Korea; Siân Lindley, sianl@microsoft.com, Microsoft Research, UK; Sarita Schoenebeck, yardi@umich.edu, University of Michigan, USA.

Permission to make digital or hard copies of part or all of this work for personal or classroom use is granted without fee provided that copies are not made or distributed for profit or commercial advantage and that copies bear this notice and the full citation on the first page. Copyrights for third-party components of this work must be honored. For all other uses, contact the owner/author(s).

(C) 2020 Copyright held by the owner/author(s).

2573-0142/2020/10-ART162

https://doi.org/10.1145/3415161

Proc. ACM Hum.-Comput. Interact., Vol. 4, No. 2, Article 162. Publication date: October 2020. 